\section{Gategory}

Synthesis of Materials and Unnatural Products

\section{Key words}

photochromic dyes

HABI (hexaarylbiimidazole)

thermal bleaching

K. FUJITA, S. HATANO, D. KATO, J. ABE* (AOYAMA GAKUIN UNIVERSITY, KANAGAWA, JAPAN)

Photochromism of a Radical Diffusion-Inhibited Hexaarylbiimidazole Derivative with Intense Coloration and Fast Decoloration Performance

Org. Lett. 2008, 10, 3105-3108.

\title{
Rapidly Switching Photochromic Dyes
}<smiles>CC(=O)OCC(O)c1ccc(-c2nc(-c3ccccc3)c(-c3ccccc3)[nH]2)cc1</smiles>

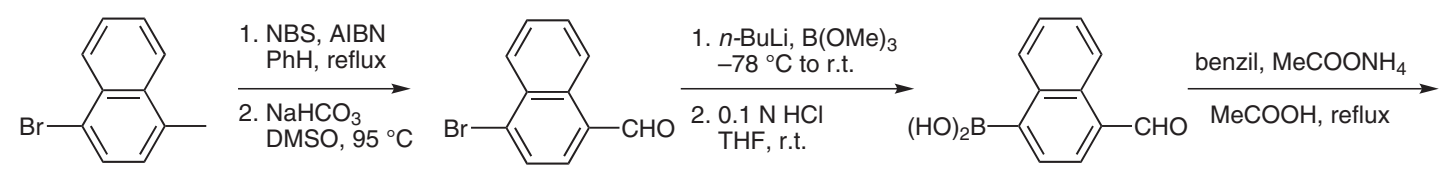

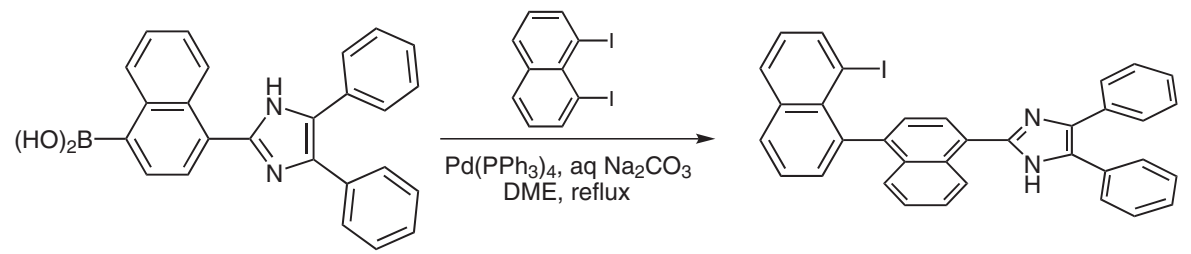

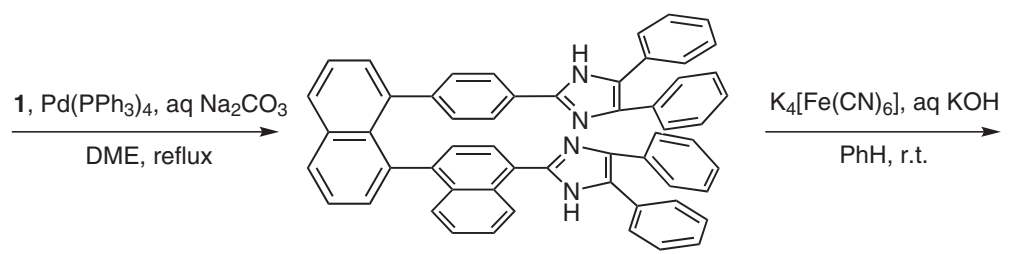
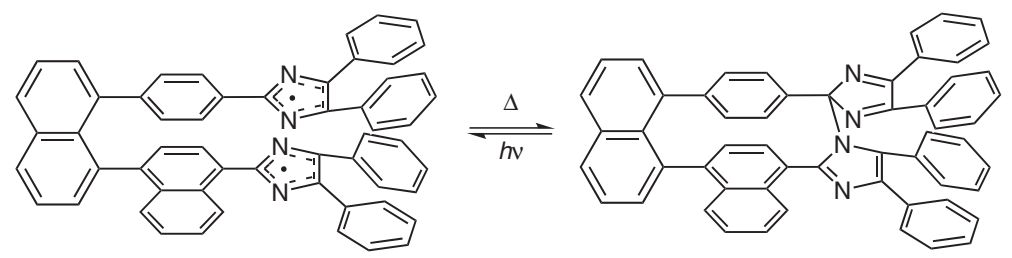

Significance: The authors report the design and synthesis of a new photochromic radical diffusioninhibited hexaarylbiimidazole. By introducing one naphthalene moiety to create a heterodimer, they have expanded the range of absorption to include all visible light. Upon UV irradiation the colorless compound turns green with a thermal bleaching rate of $t_{1 / 2}=260 \mathrm{~ms}$ at $295 \mathrm{~K}$ such that decoloration occurs faster than diffusion of the colored species.
Comment: There are many potential applications for organic photochromic compounds including lithography and optical information processing. To be useful it is important that these compounds can switch rapidly between the colored and colorless states for many cycles. The authors use rational design to improve both of these properties and demonstrate the utility of organic synthesis in the field of photochromic dyes. 